\title{
Profile, Pattern and Outcome of Shri Amaranth Ji Yatri Patients attending Sher-i-Kashmir Institute of Medical Sciences, Srinagar, India during Holy Yatra of 2017
}

\author{
G H Yatoo ${ }^{1}$, Mubashar Mashqoor Mir ${ }^{2}$ and Mohammad Sarwar Mir ${ }^{3 *}$ \\ ${ }^{1}$ Department of Hospital Administration, SKIMS, India \\ ${ }^{2}$ Department of Dermatology, GMC, India \\ ${ }^{3}$ Department of Hospital Administration, SKIMS, India \\ *Corresponding author: Mohammad Sarwar Mir, Senior Resident, Department of Hospital Administration, SKIMS, Srinagar, India
}

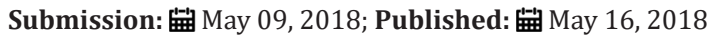

\begin{abstract}
Introduction: Located deep in the Himalayas, the cave of Amarnath is one of the holiest pilgrimage site for Hindus in general and Shiva followers in particular. It is regarded to be the abode of Lord Shiva. Because of high altitude, rough terrain, harsh weather, pilgrims are prone to many illnesses which sometimes these prove fatal.
\end{abstract}

Objective: To study the profile, pattern and outcome, among Shri Amarnath Ji yatri patients attending SKIMS in year 2017.

Methodology: A prospective study was carried out during the yatra period, all pilgrims of Shri Amarnath ji Yatra who were referred to SKIMS from July-August 2017 were studied and the patients were followed from admission till discharge. The profile, pattern and outcome of illness in Yatris attending Yatra in the year 2017 was compared with the results of year 2011 and 2015.

Results: Out of 97 patients received at SKIMS, 54(55.67\%) were having minor ailments and were seen on OPD basis, 43(44.32\%) were admitted. $32(74.41 \%)$ admitted were males at the time of arrival 14(32.5\%) were Road traffic Accidents followed by 7 patients (16.27\%) who were Acute Myocardial Infarction. Out of 43 admitted patients 36 (83.7\%) patients improved, 1(2.32\%) were discharged on request, 1(2.32\%) was referred and $5(11.62 \%)$ expired.

Conclusion: Comparison of the present study with previous studies in year 2011 AND 2015 shows that the no. of injury patients had increased significantly in present study and RTA victims formed significant proportion of cases. In addition more number of patients had expired.

Keywords: Pilgrimage; Amarnathji yatra; Illness; High altitude

\section{Introduction}

Pilgrimage, a journey resulting from religious causes, externally to a holy site, and internally for spiritual purposes and internal understanding is one of the religious and cultural phenomena most common to human society throughout the world. Pilgrimage have powerful political, economic, social and cultural implications, and can affect world trade and health. It is an important subject due to its scope and spatial influence [1]. The holy cave shrine of Amarnath is one of the important pilgrimage sites of Hinduism and is one such site of great reverence for the Hindus. It is such a place that attracts lakhs of devotees and tourists across the country (even foreigners) every year culminating into a sacred atmosphere and religious fervor [2]. The 130-ft high holy cave of "Baba Amaranth Ji," situated in the Northern Indian state of Jammu and Kashmir at a height of $13,000 \mathrm{ft}(3882 \mathrm{~m})$ and about $141 \mathrm{Kms}$ from Srinagar, the summer capital of Jammu and Kashmir and believed to be the abode of Lord Shiva. The cave shrine is visited by thousands of devotees each year over a 6-week period starting from the last part of the month of June; the pilgrimage termed as "Amarnath Yatra." The Amarnath Holy Cave standing at 3,888m is located in a narrow gorge at the farther end of the Lidder valley in South Kashmir 
(Figure 1). Two routes are available to the pilgrims, the longer route through Pahalgam (414km from Jammu) and the relatively short
Baltal route (363km from Jammu). The Yatra usually lasts for 45 days, midsummer every year [3].

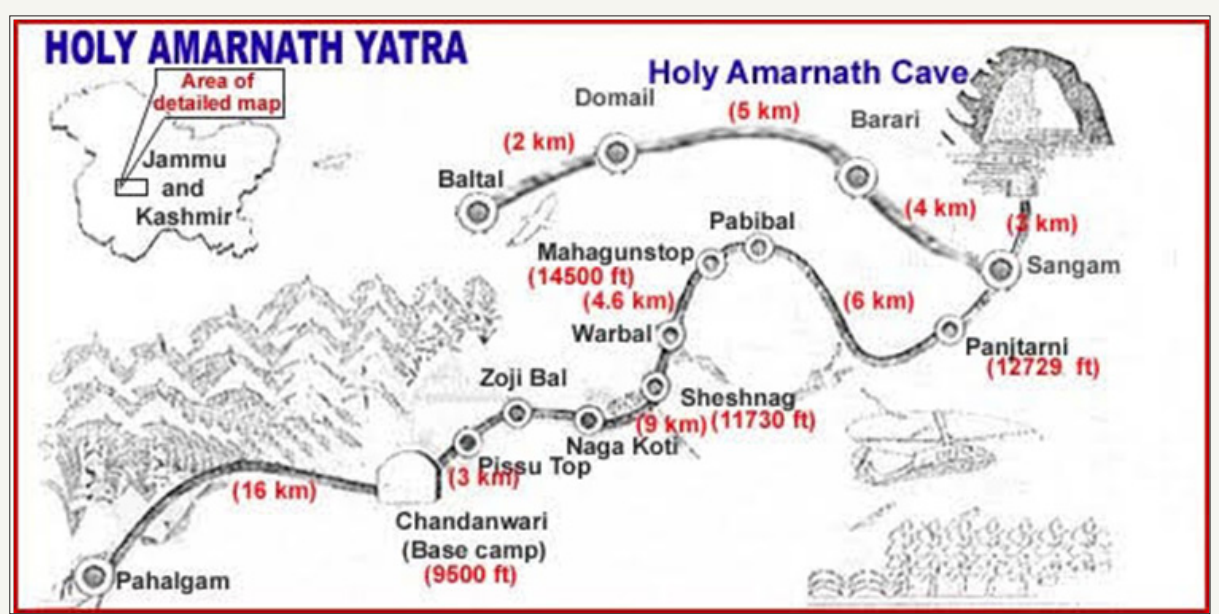

Figure 1: Showing the route, altitude and location of the Holy Cave.

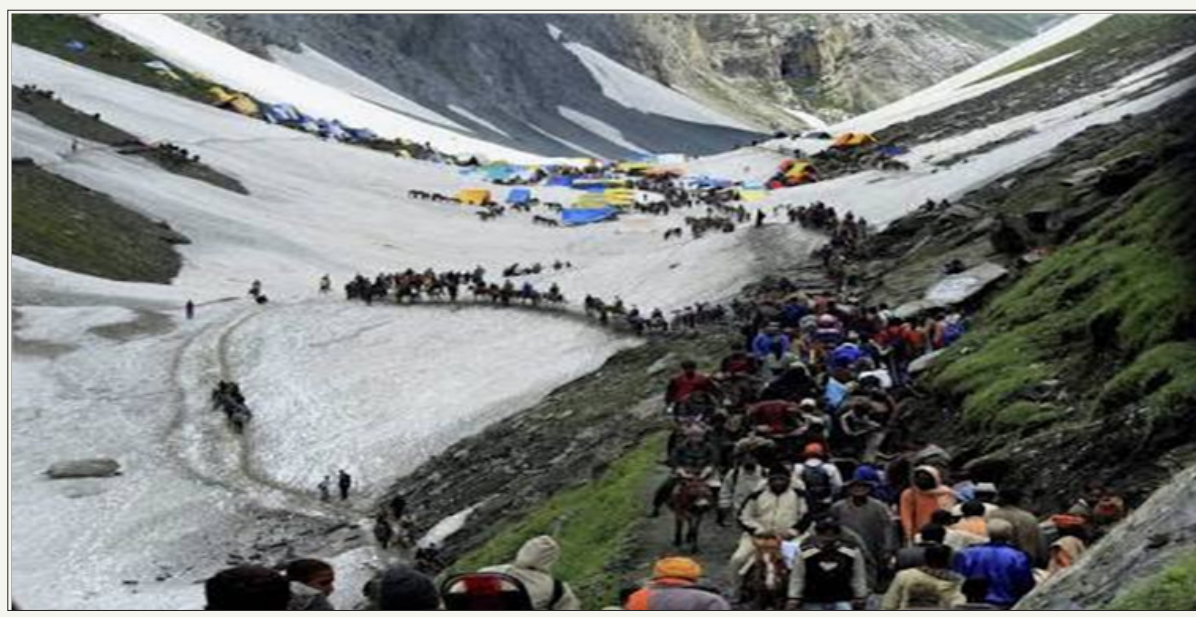

Figure 2: Showing the tough terrain on the way to the cave.

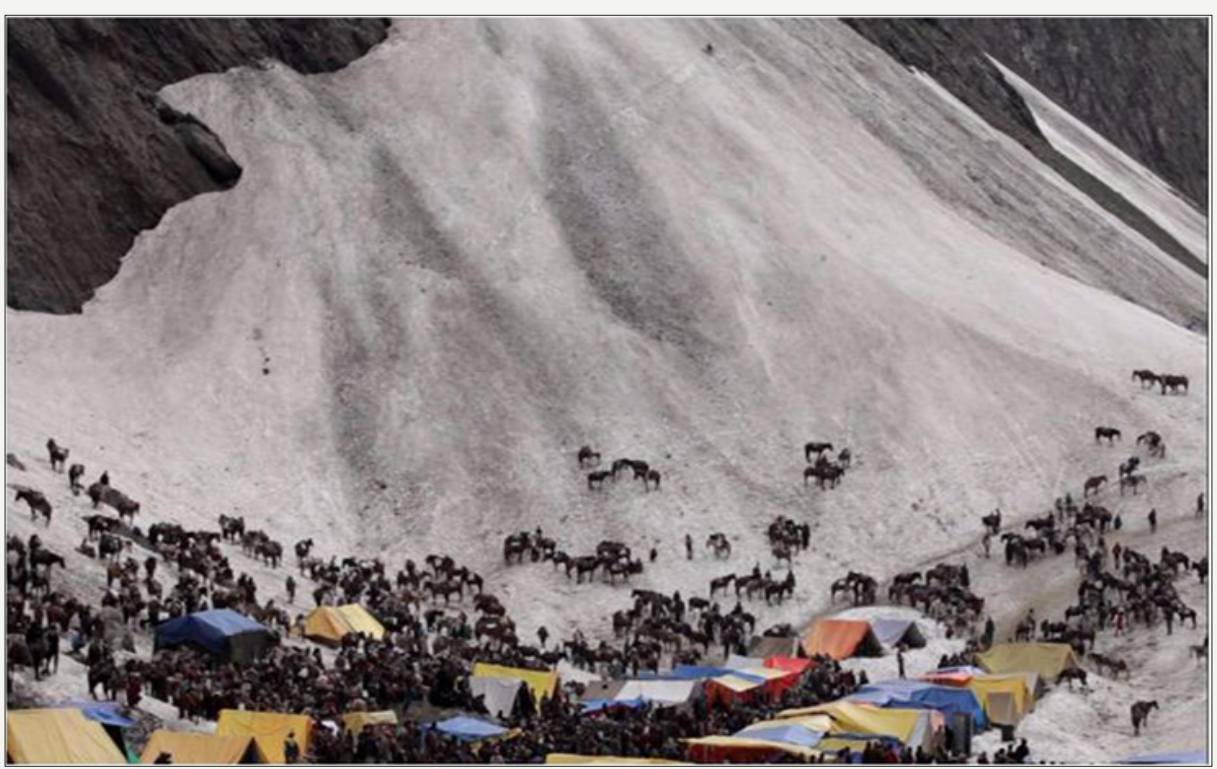

Figure 3: Showing the Glaciers enroute to holy cave. 
Because of high altitude, rough terrain, harsh weather, pilgrims are prone to many illnesses including respiratory and gastrointestinal infections, food poisoning, fall from height, road traffic accidents, and high altitude pulmonary edema (HAPE) and sometimes these prove fatal [4]. During the Yatra period, Department of Health, Govt. of Jammu and Kashmir usually establishes special medical camps en-route to Amaranth Ji cave. The patients not manageable in these camps are referred to different secondary and tertiary care hospitals in valley. Sher-i-Kashmir institute of medical sciences is a super specialty teaching university hospital catering to all the three provinces of Jammu and Kashmir State. Most of the Amaranth Ji Yatra patients requiring super-specialty care are referred to this institute for treatment [5]. The study was done to identify profile, pattern and outcome of yatri patients attending SKIMS in 2017 and to compare the results with studies of 2011 and 2015 (Figure 2 \& 3).

\section{Material and Methods}

A prospective study along was carried out at SKIMS a 800 bedded super specialty hospital of Jammu and Kashmir state. All pilgrims of Shri Amarnath Ji Yatra who were referred to SKIMS from July-August 2017 were studied. Data was collected and entered in a predesigned and pretested proforma. The details of the yatri patients that was recorded included gender, age, domicile status, diagnosis and outcome of the treatment. The patients were followed from admission till discharge/death. The pattern and outcome of illness in Yatris attending Shri Amarnath Ji Yatra in the year 2017 was compared with the results of previous analysis of 2011 and 2015.

\section{Data Entry and Statistical Analysis}

Data was collected, coded and analyzed using SPSS software (Version 20) on Windows 7, and a simple descriptive analysis was calculated for numerical data.

\section{Results}

A total of 97 yatri patients received were admitted 43(44.3\%) in Emergency Medicine Department of SKIMS during the yatra period of July-August 2017.

\section{Gender wise distribution}

Among total of 43 yatris admitted at SKIMS, 21(75\%) were males and 7(25\%) were females (Table 1 ).

Table 1: Gender wise distribution.

\begin{tabular}{|c|c|c|}
\hline Gender & Frequency & Percentage \\
\hline Male & 32 & $74.40 \%$ \\
\hline Female & 11 & $25.60 \%$ \\
\hline Total & 43 & $100.00 \%$ \\
\hline
\end{tabular}

\section{Age wise distribution}

13 yatris (30.235) were in the age group 31-40 years followed by 12 patients (27.9\%) in the age group 21-30 years. So majority of the patients were in the age of 21-40 years (Table 2).
Table 2: Age wise distribution.

\begin{tabular}{|c|c|c|}
\hline Age Groups & Frequency & Percentage \\
\hline $11-20$ & 2 & $4.65 \%$ \\
\hline $21-30$ & 12 & $27.90 \%$ \\
\hline $31-40$ & 13 & $30.23 \%$ \\
\hline $41-50$ & 9 & $20.90 \%$ \\
\hline $51-60$ & 4 & $9.30 \%$ \\
\hline $61-70$ & 2 & $4.65 \%$ \\
\hline$>70$ & 1 & $2.32 \%$ \\
\hline Total & 43 & $100.00 \%$ \\
\hline
\end{tabular}

\section{Geographical distribution}

Out of the 43 patients, 14 patients $(32.5 \%)$ were from west region of India, Gujarat and its adjoining areas (Table 3).

Table 3: Geographical distribution.

\begin{tabular}{|c|c|c|}
\hline Geographical Area & Frequency & Percentage \\
\hline North India & 12 & $27.90 \%$ \\
\hline West India & 14 & $32.50 \%$ \\
\hline Central & 11 & $25.58 \%$ \\
\hline East India & 6 & $13.95 \%$ \\
\hline Total & 43 & $100.00 \%$ \\
\hline
\end{tabular}

\section{Admitting department wise distribution of yatri patients}

Out of 43 patients, $18(41.86 \%)$ were admitted in neurosurgery, followed by 9 patients (20.9\%) in general medicine seven patients in cardiology (16.27\%)(Table 4).

Table 4: Department wise distribution.

\begin{tabular}{|c|c|c|}
\hline Department & Frequency & Percentage \\
\hline General medicine & 9 & $20.90 \%$ \\
\hline Neurosurgery & 18 & $41.86 \%$ \\
\hline Cardiology & 7 & $16.27 \%$ \\
\hline Endocrinology & 2 & $4.65 \%$ \\
\hline Neurology & 3 & $6.97 \%$ \\
\hline $\begin{array}{c}\text { Cardiothoracic and } \\
\text { Vascular Surgery }\end{array}$ & 2 & $4.65 \%$ \\
\hline General surgery & 3 & $4.65 \%$ \\
\hline Plastic Surgery & 43 & $6.97 \%$ \\
\hline Total & 2 & $100.00 \%$ \\
\hline
\end{tabular}

\section{Distribution of yatri patients as per main diagnosis}

Out of 43 cases, 14 patients (32.5\%) were referred as road traffic accidents, 7 patients (16.27\%) were of myocardial infaraction. In addition two firearm injury yatri patients were also received (Table 5). 
Table 5: Distribution of yatri patients as per main diagnosis.

\begin{tabular}{|c|c|c|}
\hline Diagnosis & Frequency & Percentage \\
\hline Road traffic accidents & 14 & $32.50 \%$ \\
\hline Myocardial infraction & 7 & $16.27 \%$ \\
\hline HACE & 6 & $13.85 \%$ \\
\hline Fall from height & 5 & $11.62 \%$ \\
\hline HAPE & 3 & $6.97 \%$ \\
\hline Gas Cylinder Blast & 3 & $6.97 \%$ \\
\hline Firearm Injury & 2 & $4.64 \%$ \\
\hline Diabetic Ketoacidosis & 1 & $2.32 \%$ \\
\hline Hit by Shooting Stone & 43 & $2.32 \%$ \\
\hline Total & & $100.00 \%$ \\
\hline
\end{tabular}

\section{Outcome of treatment}

Majority (83.7\%) of the patients were discharged in clinically stable band improved condition condition, five patients expired while as one patient each was discharged on request and referred to higher centre (Table 6).

Table 6: Outcome of treatment.

\begin{tabular}{|c|c|c|}
\hline Treatment & Frequency & Percentage \\
\hline Improved & 36 & $83.70 \%$ \\
\hline $\begin{array}{c}\text { Referred to higher } \\
\text { centre }\end{array}$ & 1 & $2.32 \%$ \\
\hline Discharge on request & 1 & $2.32 \%$ \\
\hline Expired & 5 & $11.62 \%$ \\
\hline Total & 43 & $100.00 \%$ \\
\hline
\end{tabular}

\section{Discussion}

Amarnath, abode of Shiva is an important site of hindu pilgrimage. It is dedicated to Lord Shiva. Lacs of devotees visit the Amarnath cave every year in the month of July-August to see an ice stalagmite formed inside the cave. The cave is situated at a high altitude difficult mountainous terrain with harsh weather conditions. Because of high altitude, rough terrain, harsh weather, pilgrims are prone to many illnesses including respiratory and gastrointestinal infections, food poisoning, fall from height, road traffic accidents, and high altitude pulmonary edema (HAPE) and sometimes these prove fatal [6].

During this yatra devotees are prone to illness and accidents, for which special medical treatment facilities are provided enroute to the Amarnath cave. Patients who need special care are referred to state level health care centers like Shri Maharaja Hari Singh (SMHS) Hospital, Bone and Joint Hospital (BJH) and Sher-i-Kashmir Institute of Medical Sciences (SKIMS). Two routes are available for Yatra, one is via Pahalgam situated in south Kashmir and another is via Baltal situated in central Kashmir nearer to Srinagar. As SKIMS is the nearest tertiary care center enroute Baltal so Yatris patients who need special care are referred to SKIMS for management [6]. High altitude religious excursions are very common in India and many experience ill effects of high altitude. Due to over enthusiasm, many people try to conceal their illness and they face serious emergencies during the pilgrimage, posing serious problems to the organizers and the authorities. The situation is further aggravated by difficult terrains, lack of infrastructure and acclimatization. To avoid fatalities government had made it mandatory to undertake a medical checkup before allowing any such pilgrimage [3].

A study by Yatto et al. [5] in 2011, recommended the pre health check up of the yatris before starting pilgrimage. Also it recommended upgradation of health facilities along the yatra route. In 2015 study by Yatoo et al. [6], it showed significant reduction in number of referral patients to SKIMS and it was attributed to adherence to the previously given recommendations. In 2017, our study showed that Road traffic Accidents and other trauma was the leading cause for admission, followed by Myocardial Infarction and HACE. Trauma during pilgrimage is a real surgical problem which deserves more attention. Orthopedic and neurosurgical cases were the most common surgical cases during Hajj period [7,8]. Poorly acclimatized people from the plains are at high risk of developing various manifestations of high altitude illness, non-traumatic surgical emergencies and hyperglycemic emergencies during the holy pilgrimage to the Amarnath cave shrine. Yatris agreed to have concealed their ailments while seeking medical certificate from medical practitioner in their intense desire to undertake the pilgrimage and there was generally lack of awareness of the challenges posed by the journey. These indicate a knowledge deficit, which needs to be adequately addressed through intensive educational efforts aimed at better preparing the yatris for the holy trek [9].

\section{Conclusion}

Keeping in view the suggestions in our previous studies of Yatri patients in 2011 and 2015 that

A. Pre-yatra checkup should be done before registering the yatris for Amarnath pilgrimage and those with co morbidity should be allowed to visit the Holy cave only after special travel arrangements taking due cognizance of the medical illness.

B. Health care infrastructure should be upgraded on way to Amarnath cave.

The pattern and outcome of illness in Yatri patients who were referred to SKIMS in 2017 was compared with results of previous analysis of 2011 and 2015. It was observed that in 2011: Total Yatri patients received 185, out of which $100(54 \%)$ patients were having minor ailment and were not admitted. 85(45\%) Yatri patients were admitted for treatment. Total recovered were 77(90\%), 2(2.4\%) Left against Medical Advise (LAMA), 1(1.2\%) was discharged on request and 5(5.9\%) expired [3]. In 2015 study: Total Yatri patients received were 61, out of which 33 had minor ailment and were not admitted. Out of 28 Yatri patients admitted, 12(42.95) improved, $6(21.4 \%)$ recovered, $1(3.6 \%)$ was referred to Medical College for further treatment, $8(28.6 \%)$ were discharged on request and $1(3.6 \%)$ expired.

In Present Study, Out of 97 patients received at SKIMS, $54(55.67 \%)$ were having minor ailments and were seen on OPD 
basis, 43(44.32\%) were admitted. 32(74.41\%) admitted were males at the time of arrival $14(32.5 \%)$ were Road traffic Accidents followed by 7 patients (16.27\%) who were Acute Myocardial Infarction. Out of 43 admitted patients $36(83.7 \%)$ patients improved, $1(2.32 \%)$ were discharged on request, $1(2.32 \%)$ was referred and 5(11.62\%) expired. Comparison of the present study with previous studies in year 2011 AND 2015 shows that the no. of injury patients had increased significantly in present study and RTA victims formed significant proportion of cases. In addition more number of patients had expired.

\section{References}

1. Bilal AB, Sidrat-Ul MA, Syed NZG, Fareed AR, Samira K, et al. (2017) Study on geography of pilgrimage tourism and environment: A case study of Kashmir valley. International Journal of Engineering and Management Research 7(4): 162-169.

2. Shah AR (2013) A sociology lens of pilgrimage tourism in Kashmir valley: a case of holy Amarnath pilgrimage. The Tibet Journal 38(3-4): 57-85.
3. (2018) Darshan of shri him shiv lingam in shri Amarnathji holy cave (Gufa).

4. Jagdeep S, Gorea RK, Aggarwal AD (2005) Victimology of high altitude pilgrimage. Journal of Punjab Academy of Forensic Medicine \& Toxicology 5: 35-38.

5. Yatoo GH, Amir SK, Malik A, Shariq RM (2011) Profile of patients attending SKIMS srinagar during 2011 Amarnathji yatra. Journal of Medical Sciences 15(2): 170-173.

6. Yatoo GH, Amir SK, Malik A, Shariq RM (2016) Profile of Amarnath ji yatri patients attending sher-i-kashmir institute of medical sciences, srinagar, India during the year 2015. International Journal of Medicine and Pharmaceutical Science (IJMPS) 6(6): 59-66.

7. Al-Harthi AS, Al-Harbi M (2001) Accidental injuries during muslim pilgrimage. Saudi Med J 22(6): 523-525.

8. Khuroo MS (2003) Profile of hajj pilgrims as depicted from inpatient hospital record. Saudi Med J 24: 1073.

9. Koul PA, Umar HK, Tajamul H, Ajaz NK, Sajjad M, et al. (2013) High altitude pulmonary Edema among Amarnath yatris. Lung India 30(3): 193-198.
Creative Commons Attribution 4.0 International License

For possible submissions Click Here

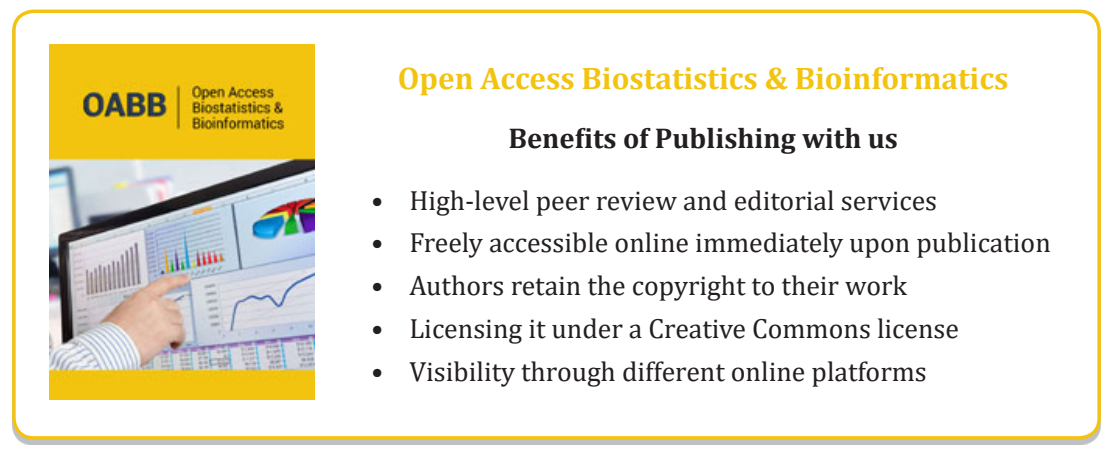

